\title{
Vaginal mass caused by a lately recognized congenital bladder diverticulum
}

\author{
Kürşad Zengin, MD; ${ }^{*}$ Serhat Tanik, MD; ${ }^{*}$ Mesut Gürdal, MD; ${ }^{*}$ Aylin Okur, MD; ${ }^{\dagger}$ Betül Zengin, $M D^{\S}$
}

*Faculty of Medicine, Department of Urology, Bozok University, Yozgat, Turkey; †Faculty of Medicine, Department of Radiology, Bozok University, Yozgat, Turkey; §Radiology Clinics, Yozgat State Hospital, Yozgat, Turkey

Cite as: Can Urol Assoc J 2013;7(9-10):e634-6. http://dx.doi.org/10.5489/cuaj.247

Published online October $9,2013$.

\section{Abstract}

Congenital bladder diverticula are strongly associated with vesicoureteral reflux (VUR), and are mostly present in childhood. The most common symptom is urinary tract infection at the time of admission. The diverticulum is usually solitary and its location is near the ureteral orifice, which is probably the main cause of VUR. We report a woman who presented with a vaginal mass located on the right inferior part of the external urethral meatus. The patient had a history of recurrent urinary tract infection and right nephrectomy due to VUR nephropathy. We examined her with cystography, computerized tomography, and cystoscopy. The cystoscopic examination was very diagnostic in our patient. The patient underwent diverticulectomy, and after 6 months of followup, her complaints had completely disappeared.

\section{Introduction}

Bladder diverticulum represents a herniation of the bladder urothelium through the muscularis propria of the bladder wall. The outside wall of the diverticulum may contain some residual scattered strands or bundles of smooth muscle; however these are disorganized and nonfunctional. Therefore, bladder diverticula generally empty poorly during micturition, leaving a large postvoid residual urine volume that results in the characteristic findings on presentation and imaging. Bladder diverticula may be congenital or acquired. ${ }^{1}$

Congenital bladder diverticulum usually presents during childhood, with a peak incidence in children under 10 years old. ${ }^{2}$ It is usually solitary, but larger in comparison with the acquired ones and more common in boys than girls. ${ }^{3}$ The most common presentation of congenital bladder diverticulum is urinary tract infection. ${ }^{4}$ Congenital bladder diverticulum may occur in patients with normal voiding dynamics in the absence of bladder outlet obstruction, but secondary bladder outlet obstruction may occur when the diverticulum extends distally towards the bladder neck. ${ }^{5,6}$ We report an unusual presentation of congenital bladder diverticulum as a vaginal mass and cause of recurrent urinary tract infection.

\section{Case report}

A 25-year-old woman presented with a vaginal mass located on the anterior wall of the vagina adjacent to external urethral meatus. She complained of recurrent urinary tract infections. She described a vaginal mass increasing in size just before urination. After urination, she noticed that the size of this mass always decreased. She had history of right nephroureterectomy; she had vesicoureteral reflux nephropathy when she was 18 years old. The genital examination revealed a non-tender cystic mass adjacent to the external urethral meatus. Urinary examination was compatible with urinary tract infection and the culture revealed E.coli colonization. While she was treated with approprite antibiotics, she was examined with ultrasonography, cystography, and abdominal computed tomography (CT). Ultrasonography revealed a polypoid lesion at the right ureterovesical junction, and hyperechoic cellular debris in the bladder. Cystography revealed a bladder diverticulum beginning from the right wall of bladder, extending downwards and ending near the right vaginal wall. The CT scan showed a bladder diverticulum begining from the right wall of the bladder extending downwards, and a polypoid lesion of $19 \times 9 \mathrm{~mm}$ protruding into the bladder (Fig. 1).

A diagnostic cystoscopy was performed under local anesthesia with $0.5 \%$ bupivacaine solution and $2 \%$ lidocaine-gel. A wide-mouthed diverticulum was observed just beneath the right ureteric orifice. When passing a 9 Fr ureterorenoscopy through the mouth of the diverticulum, we found cellular debris at the base of diverticulum, and no evidence of malignancy. When performing cystoscopy, we noticed that the 


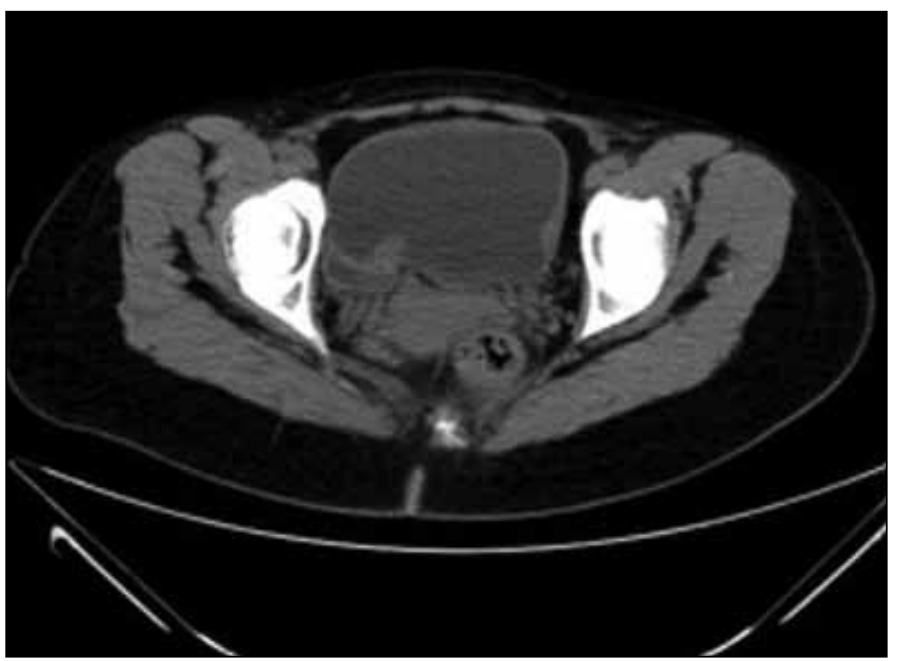

Fig. 1. A computed tomography scan of bladder diverticulum and polypoid lesion protruding into the bladder.

vaginal mass became larger, and when sterile methylene blue was administered through the cystoscope, the vaginal mass appeared bluish (Fig. 2).

Under general anesthesia, the patient underwent a combined extravesical and intravesical approach to excise the diverticulum. The bladder was closed in 2 layers. She was given $15 \mathrm{mg}$ propiverine hydrochloride twice a day postoperatively. The urethral catheter was removed at 2 weeks. Postoperative cystography was normal (Fig. 3). The patient attended monthly follow-ups. At 6 months, she had no urinary tract infection and the vaginal mass disappeared after diverticulectomy.

\section{Discussion}

Bladder diverticulum may be congenital or acquired. ${ }^{1}$ The incidence of bladder diverticulum in children is $1.7 \% .^{7}$ The diverticulum generally empties poorly during micturition, leaving a large postvoid residual urine volume that results in the characteristic findings on presentation and imaging. Congenital bladder diverticulum is usually solitary, and seen mostly in males. It is usually associated with VUR, and located lateral or posterior to the ureteral orifice. On the other hand, acquired diverticula are usually multiple, and typically found in association with significant bladder trabeculation. ${ }^{4,8,9}$ The primary cause in patients with congenital bladder diverticula appears to be a congenital weakness at the level of the ureterovesical junction..$^{10}$ As the diverticulum enlarges, it may incorporate the ureteral orifice, thereby displacing the ureteral orifice from the trigone, resulting in the loss of the submucosal tunnel. This deranged anatomy results in VUR. ${ }^{11}$

Congenital bladder diverticula most often present with urinary tract infection, but hematuria, abdominal pain, or an abdominal mass may also be present. Inguinal hernias containing bladder diverticula have also been reported. ${ }^{4,12}$

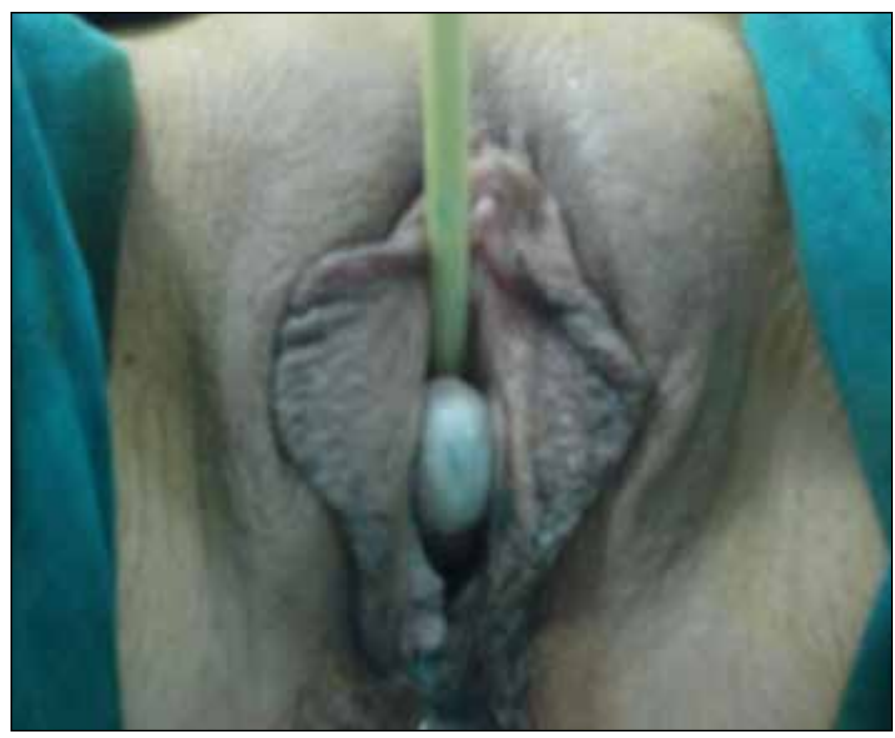

Fig. 2. Vaginal mass appeared bluish when methylene blue was administered via cystoscope.

Hydronephrosis may be related to some causes, such as obstruction of the ureter, an underlying urodynamic abnormality that resulted in the formation of the diverticulum, or vesicoureteral reflux in association with the diverticulum, inflammation; it may also be completely unrelated to the bladder diverticulum. ${ }^{13} \mathrm{~A}$ very high prevalence of ipsilateral vesicoureteral reflux has been noted with congenital bladder diverticula. ${ }^{14}$

One study noted reflux in 83 of 89 diverticula associated with ureteric units. ${ }^{5}$ Other considerations in the evaluation

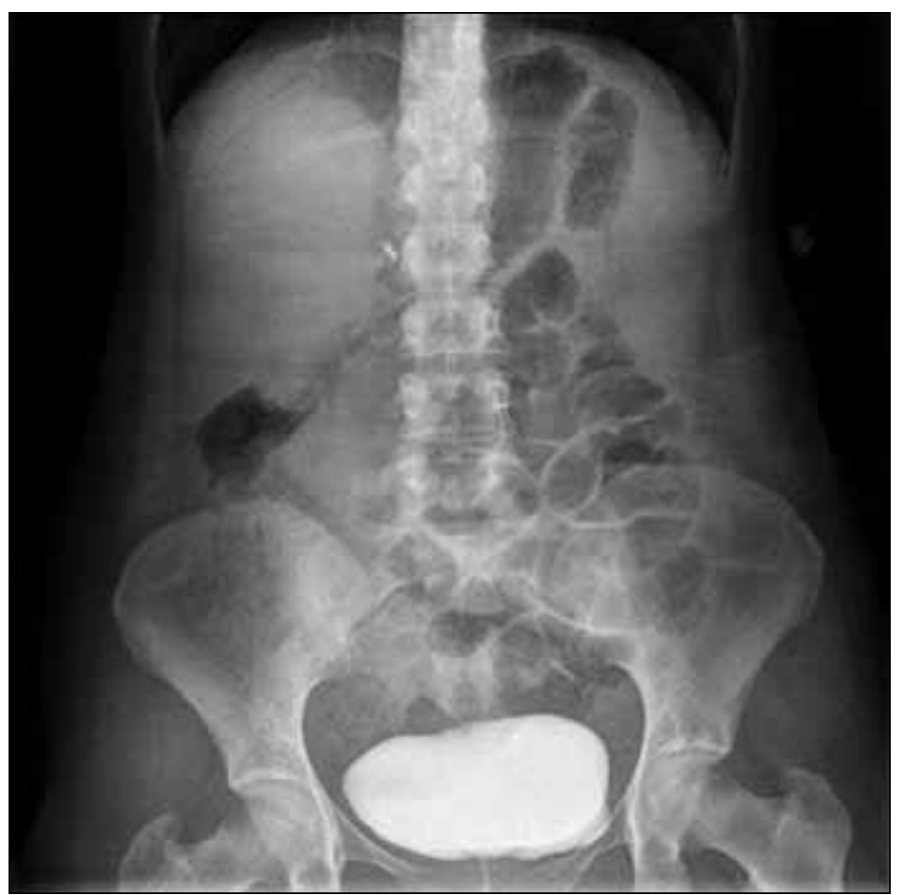

Fig. 3. Postoperative cystography. 
and management of bladder diverticula include the development of stones within the diverticulum, ureteral obstruction, and rare but life-threatening complication of perforation and/ or rupture of the bladder diverticulum. ${ }^{15,16}$

There are very few reports of congenital bladder diverticulum diagnosed in adults. Palmero and colleagues reported a case of congenital bladder diverticulum diagnosed in adulthood with hydroureteronephrosis. It was also reported that a narrowing of the urethra occured at the point of bladder entry in intravenous urethrography. Cystography revealed the diagnosis of bladder diverticulum. There was not VUR in that case so an endoscopic surgical opening of the diverticular neck was the treatment of choice. ${ }^{17}$

Incidentally found congenital or acquired bladder diverticula may require no further therapy unless it is associated with persistent symptoms, recurrent infections, obstruction, stones, malignancy, or other complicating factors such as ipsilateral VUR. Therefore, bladder diverticulectomy is indicated to treat symptoms related to the diverticulum, or for the major complications directly related to it. These complications include chronic relapsing urinary tract infection, stones within the diverticulum, carcinoma or premalignant change, and, finally, upper urinary tract deterioration as a result of obstruction or reflux. ${ }^{1}$

\section{Conclusion}

In our case, the patient was 25 years old, and had undergone right nephroureterectomy 7 years ago because of VUR nephropathy. After nephrectomy, she had continued to suffer recurrent urinary tract infections. She also noted a mass on the anterior wall of vagina on the right side of the external urethral meatus. Congenital bladder diverticulum is strongly associated with VUR. In any patient diagnosed as unilateral VUR or hydroureteronephrosis, detailed investigation of congenital bladder diverticula, especially for young patients, should be kept in mind in the differential diagnosis.
This paper has been peer-reviewed.

\section{References}

1. Rovner ES. Bladder and female urethral diverticula. In Kavoussi LR, Partin AW, Novick AC, Peters CA eds, Campbell-Walsh Urology, 10th edn, Chap 78. Philadelphia: Saunders;2012:2262-89. http://dx.doi. org/10.1016/B978-1-4160-6911-9.00078-5

2. Boechat MI, Lebowitz RL. Diverticula of the bladder in children. Pediatr Radiol 1978;7:22-8. http:// dx.doi.org/10.1007/BF00975333

3. Mitra SK, Chakraborty JN. Congenital bladder diverticulum presenting as bladder oufflow obstruction and obstructive uropathy. Report of 6 cases and review of literature. J Indian Assoc Pediatr Surg 2002;7:25-8.

4. Garat JM, Angerri 0, Caffaratti J, et al. Primary congenital bladder diverticula in children. Urology 2007;70:984-8. http://dx.doi.org/10.1016/i.urology.2007.06.1108

5. Barrett DM, Malek RS, Kelalis PP. Observations on vesical diverticulum in childhood. J Urol 1976; 116:2346.

6. Oge 0 , Gemalmaz H, Ozeren B. Acute urinary retention in a child caused by a congenital bladder diverticulum. J Pediatr Surg 2002;37:926-7. http://dx.doi.org/10.1053/ipsu.2002.32915

7. Blane JE, Zerin JM, Bloom DA. Bladder diverticula in children. Radiology 1994;190:695-7.

8. Evangelidis A, Castle EP, Ostlie DJ, et al. Surgical management of primary bladder diverticula in children. J Pediatr Surg 2005;40:701-3. http://dx.doi.org/10.1016/i.jpedsurg.2005.01.003

9. Wesselhoeft CWJ, Perlmutter AD, Berg S, et al. Pathogenesis and surgical treatment of diverticulum of the urinary bladder. Surg Gynecol Obstet 1963;116:719-25.

10. Hutch JA, Ayres RD, Loquvam GS. The bladder musculature with special reference to the ureterovesical junction. J Urol 1961;85:531-9.

11. Alsam F, Syed JA, Nadeem N, et al. Acute urinary retention as a result of a bladder diverticulum. Int $J$ Urol 2006;13:628-30. http://dx.doi.org/10.1111/i.1442-2042.2006.01368.x

12. Schewe J, Brands EH, Pannek J. The inguinal bladder diverticulum: a rare differential diagnosis of hernias. Int Urol Nephrol 2000;32:255-6. hitp://dx.doi.org/10.1023/A:1007110429906

13. Kwan DJ, Lowe FC. Congenital bladder diverticulum: an unusual presentation with abdominal mass, urinary retention, and renal failure in a young adult. Urol Radiol 1992;14:194-6. http://dx.doi.org/10.1007/ BF02926928

14. Amar AD. Familial vesicoureteral reflux. J Urol 1972;108:969-71.

15. Sharma R, Mondal A, Sherigar R, et al. Giant diverticulum of urinary bladder causing bilateral hydronephrosis in an adult. Diagnostic features on radionuclide scintigraphy. Clin Nucl Med 1997;22:385-7. http:// dx.doi.org/10.1097/00003072-199706000-00008

16. Jorion JL, Michel M. Spontaneous rupture of bladder diverticula in a girl with Ehlers-Danlos syndrome. $J$ Pediatr Surg 1999;34:483-4. http://dx.doi.org/10.1016/S0022-3468(99)90506-7

17. Palmero Martí JL, Ramirez Backhaus M, Alvarez Barrera A, et al. Hutch bladder diverticula: a very uncommon entity in adults. Arch Esp Urol 2012;65:636-9.

Correspondence: Kürşad Zengin, Faculty of Medicine, Department of Urology, Bozok University, Medrese Mh., 66100 Yozgat, Turkey; kursadzengin@yahoo.com 